(c) 2010 IEEE. Personal use of this material is permitted. Permission from IEEE must be obtained for all other uses, in any current or future media, including reprinting/republishing this material for advertising or promotional purposes, creating new collective works, for resale or redistribution to servers or lists, or reuse of any copyrighted component of this work in other works. 


\section{Balanced Scorecard-Based Approach to Ascertain the Quality of Education}

\author{
Khresna Bayu Sangka \\ Digital Ecosystem of Business Intelligence Institute \\ (DEBII), Curtin University of Technology \\ Perth, Australia \\ khresnab@postgrad.curtin.edu.au
}

\author{
Omar Khadeer Hussain \\ Digital Ecosystem of Business Intelligence Institute \\ (DEBII), Curtin University of Technology \\ Perth, Australia \\ O.Hussain@curtin.edu.au
}

\begin{abstract}
Educational Providers should continually monitor and measure their performance in terms of delivering quality education to the students. Although the importance of such an assessment process has been stressed in the literature, no framework has been proposed that considers all the different relevant factors and determines semantically the level of the quality of education being delivered. In order to provide such an approach, in this paper we propose a framework by which the quality of education being delivered in a subject in an Indonesian university can be determined by using the Balanced Scorecard (BSC). The proposed approach will capture the different factors to be considered from the different perspectives and assimilate them to determine the quality of education. The resultant analysis will provide important inputs to the different stakeholders involved in taking appropriate measures to ensure that students' learning experiences can be maintained at a certain desired level.
\end{abstract}

Keywords: Education quality, balanced scorecard, risk analysis, risk assessment.

\section{INTRODUCTION}

The $21^{\text {st }}$ century has seen the wave of globalization become more powerful and inclusive. Advancements in technology and dynamic global changes have raised a new public awareness in Indonesia. Indonesia stands in the middle of a new open world, in which individuals perceive that they have the right to compare their lives in every respect with the lives of individuals in other nations. However, according to the Human Development Index (HDI), such levels of comparisons do not seem to be evidenced in all areas. The Human Development Index is an indicator designed to measure a nation's quality of life, access to proper education, life expectancy, living standards and the level of literacy [1]. Recent education reports have shown that the quality of education in Indonesia is not improving as much as that of other South East Asia countries or other developing countries in the world. According to the 2008 Human Development Index report, Indonesia ranked $107^{\text {th }}$ in the education sector with a score of 0.728 and in 2009 it fell to $111^{\text {th }}$ with a score of 0.840 . This clearly shows that the quality of education being delivered in Indonesia is declining. To improve this, we need an approach that investigates, identifies and then addresses the different factors which are preventing to improve the quality of education currently being delivered. What is needed is a risk analysis-based approach which on an ongoing basis identifies, assesses and manages any possible risks which threaten the quality of education being delivered, thereby ensuring that this quality is maintained at an acceptable level.

In this paper, we propose an approach by utilizing the Balanced Scorecard (BSC) that will assist an education provider in the risk identification and risk assessment phase of the risk analysis process. The output of this process will provide important considerations during the later phase of risk management. This paper is organized as follows. Section 2 discusses the previous work from the literature on improving the quality of education and justifies the selection of the BSC as the tool to carry out the risk identification and risk assessment process. In Section 3, we propose our BSC framework and discuss the goal, different objectives and key performance indicators (KPIs). In Sections 4-5, we discuss our approach of utilizing the ANP process to determine the weight of each KPI and then determining the level of quality of education. Finally in Section 6, we conclude the paper.

\section{JUSTIFICATION OF UTILIZING THE BALANCED SCORECARD FOR MEASURING THE QUALITY OF EDUCATION}

The quality of education can be improved by means of a two-step approach which involves having an effective process that determines the areas of improvement, and an effective process for decision-making and responding to the changes required $[2,3]$. In the literature, approaches have been proposed that aim to identify the factors which need to be addressed in improving the quality of education. For example, [4] states that the process of enhancing, assessing, maintaining and improving the quality of education has to be addressed using several criteria such as trust building, better collaboration and dialogue, participation in shaping the future, and a culture of evidence. These processes are developed from a measurable, specific, achievable and time line-based approach according to administrative management philosophy [4]. But apart from studying the impact of these factors, some of the other important factors that need to be considered when measuring the quality of education are: 1) the alignment of objectives with the goals; 2) efficiency in the communication of the curriculum to the students; and 3) increased reliability and accountability etc. These processes should be well established in order to ensure the delivery of consistently high levels of productivity and service quality in the higher education institution. As opposed to other organizations, increasing the 
sustainability and reputation of an educational institution is not just about improving its financial viability; it is more concerned with addressing those factors which impact on the students' learning experience in terms of the quality of education being delivered. These factors include: the relevance of curriculum content to the requirements of industry and public service, teaching and learning processes, teaching staff welfare, and the quality of teaching staff. These factors impact upon the quality of education being delivered in the classroom. However, there are also other factors outside the classroom environment which may determine the quality of education being delivered. These may include: student learning results, student and stakeholder focused results, staff competence levels, organizational operational level including key internal operational performance measures, and governance and social responsibility results. Therefore, as an integral part of the accountability process, all these non-financial factors should be identified and considered when determining the quality of education being delivered. As mentioned earlier, apart from establishing accountability, another important step to improve the quality of education is to be proactive in addressing the identified issues $[5,6]$. This is achieved by incorporating the process of risk analysis. Existing approaches in the literature do not consider all these factors; nor do they provide a process of risk analysis that incorporates accountability in the process of maintaining the quality of education. We aim to achieve it in our approach by using a Balanced Scorecard.

The Balanced Scorecard (BSC) is an integrated performance management system that enables organizations to clarify their strategy and translate it into action [7]. It takes into consideration both the financial and non-financial aspects of an organization. By measuring current performance outcomes as well as future performance drivers, the BSC provides feedback for both the internal business processes and external outcomes in order to continuously improve strategic performance [8]. It takes into consideration values and strategic objectives of the institution, the contributions of individual units to those objectives, and opens up the dialogue for real conversation. This will help to introduce the concept of accountability; managing a control system for general processes in a higher education institution is one of the key factors to successfully improve educational quality [6]. This process will help in the delivery of consistently high degrees of productivity and service quality for a fixed or decreasing cost to the organization. It has been stated in the literature that the BSC could be a powerful model for strategic positioning in a higher education institution, because it analyzes all aspects of an organization [9-11]. However, previous approaches have focused only on managing the performance of the education staff only. For example, [12] proposed a benchmark scorecard for the BSC which is implemented in the education sector based on the basic requirement of education staff performance. Such approaches, although they relate to the educational sector, do not take into consideration the different stakeholders - an essential consideration for improving the overall quality of education. To address this shortcoming, in this paper we propose a BSC-based approach to determine the level of quality of education by considering the wide range of factors required for determining the level of quality of education. The proposed approach is explained in the next section.

\section{PROPOSED BALANCED SCORECARD FRAMEWORK FOR MEASURING THE QUALITY OF EDUCATION}

The Balanced Scorecard (BSC) is an integrated performance management system that enables organizations to clarify their strategy and translate it into action [7]. In other words, it provides a comprehensive measurement system that takes into consideration all those indicators that are important for the achievement of the goal(s). The structure of the BSC is usually divided into 4 different levels as shown in Figure 1. The first level represents the goal to be achieved; the second level represents the different objectives into which this goal is divided; the third level represents the different perspectives of the balanced scorecard which are considered to achieve the goal and the fourth level represents the different key performance indicators (KPIs) that come under each perspective in order to achieve the objective.

In our case, as our aim is to determine the quality of education so that it can improved, we define the goal of the BSC as "Measuring the quality of education". The goal will be dependent on different objectives that specify in what areas the quality of education will be assessed. In other words, the goal to be achieved should be categorized or broken down into different factors that are termed the 'objective'. From the Indonesian perspective, higher education has to address three different areas: science transfer (which is related to the higher education institution as a learning and education institution), community and government outreach (related to the higher education

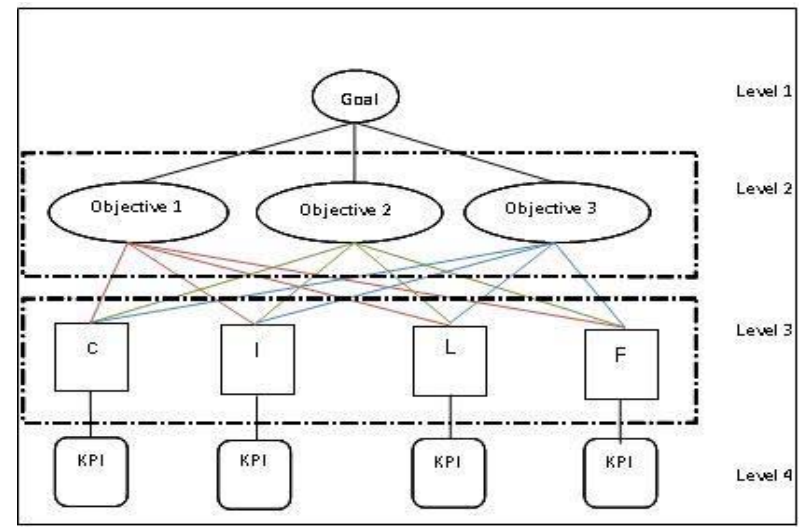

Figure 1. Balance Scorecard Framework 
institution as a public service institution), and research (related to the higher education institution as a research and development institution). The objectives can be defined as the cultivation of perspectives achievement. In our case, we categorize the goal into three major objectives by studying the higher education institution's long term strategic planning. They are:

1. Lead on the education science transfer and development.

2. Lead on the community and local government outreach.

3. Lead on the research quality and quantity.

Each of the above mentioned objectives is dependent on various factors which are termed 'indicators'. But before identifying the indicators, the perspectives of the BSC should be identified. Perspectives in BSC are group relevance indicators that must be considered if an organization is to achieve a goal. In other words, perspective in BSC simplifies the overall business process of the different factors that need to be achieved. The number of perspectives to be considered in a BSC varies according to the objectives, goals and stakeholders. It also depends on how an organization categorizes its business process. In this paper, since our focus is on educational business which is not merely a profit-oriented business, the perspectives and KPIs that have to be identified should be a combination of financial and non-financial performance metrics. Hence, we use the original perspectives from Norton and Kaplan which are Customer, Internal Process, Learning and Growth and Financial, since the relevance of these perspectives is appropriate to the existing business process in education. Customer perspective represents the satisfaction of the consumers in achieving the goals. The customers in this case include students, stakeholders, and community. Internal process perspective represents the internal process by which the aim or goal of the organization is being achieved. Learning and growth perspective represents the organization's ability and intention to change and improve its business core value in terms of sustaining and affording the customers' needs. The financial perspective considers those factors that are related to the financial cash flow of the organization.

Once the perspectives of the BSC have been identified, then the different KPIs that come under each perspective should be defined. As mentioned earlier, since the focus of an educational institution is not merely to be a profitoriented business, so the KPIs that have to be identified should be a combination of financial and non-financial performance metrics. In our approach, by studying the strategic plan of the higher education institution, we have identified 22 KPIs which are shown in Table 1. These KPIs are categorized under each perspective that is in turn dependent on each objective in order to achieve the goal.

Even though a KPI is placed under a perspective in

TABLE 1. BALANCED SCORECARD MODEL

\begin{tabular}{|c|c|c|c|}
\hline GOAL & OBJECTIVE & PERSPECTIVE & KEY PERFORMANCE INDICATOR \\
\hline \multirow{7}{*}{$\begin{array}{l}\text { Measuring the } \\
\text { quality of } \\
\text { education }\end{array}$} & \multirow[t]{2}{*}{$\begin{array}{c}\text { Lead on The Education } \\
\text { Science Transfer and } \\
\text { Development }\end{array}$} & Customer (C) & $\begin{array}{l}\text { Students' Learning Experience } \\
\text { Students' Competence } \\
\text { Students' Empowerment } \\
\text { Public Image } \\
\text { Attention to Stakeholders }\end{array}$ \\
\hline & & \multirow[t]{2}{*}{ Internal Process (I) } & $\begin{array}{l}\text { Teaching Excellence } \\
\text { Books Support } \\
\text { Learning Media Support }\end{array}$ \\
\hline & \multirow{2}{*}{$\begin{array}{l}\text { Lead on The Community } \\
\text { Services and Local } \\
\text { Government Outreach }\end{array}$} & & $\begin{array}{l}\text { Internet Connection Support } \\
\text { Service Excellence } \\
\text { Research Atmosphere } \\
\text { Partnership Excellence }\end{array}$ \\
\hline & & \multirow[t]{3}{*}{ Learning and Growth (L) } & $\begin{array}{l}\text { Lecturer Competence } \\
\text { Managerial Excellence } \\
\text { Teaching Innovation } \\
\text { Curriculum Technology }\end{array}$ \\
\hline & \multirow{3}{*}{$\begin{array}{l}\text { Lead on The Research } \\
\text { Quality and Quantity }\end{array}$} & & $\begin{array}{l}\text { Reward System } \\
\text { Journals and Publication }\end{array}$ \\
\hline & & & Tool Investment \\
\hline & & Financial $(\mathrm{F})$ & $\begin{array}{l}\text { Human Capital Investment } \\
\text { Royalty Income } \\
\text { Diversity Revenue }\end{array}$ \\
\hline
\end{tabular}


Table 1, it does not mean that it does not have any relationship with or impact upon the other perspectives or objectives. There can be an interdependent relationship between a KPI with different objectives. In other words, a KPI may be dependent upon more than one perspective. For example, the KPI student's learning experience may be related not only to the perspective customer, but also on how an institution carries out its internal process which comes under the internal process perspective as shown in Figure 2. Similarly, the weight that a KPI might have on a perspective may not be the same as on the other perspective and this will have a varying impact on each objective that has to be determined. So the appropriate weight of each KPI has to be determined according to the goal or objective to ascertain its specific importance. In the next section, we discuss the Analytic Hierarchy Process (AHP) and Analytic Network Process (ANP) proposed in the literature to determine the weights of each KPI.

\section{IV.DETERMINING THE WEIGHTS OF EACH KPI}

The Analytic Hierarchy Process (AHP) is a comprehensive framework that is designed to cope with and the irrational information when a multi-objective, multicriterion decision has to be made. The basic assumptions of AHP are that it can be used in functional independence of an upper part or cluster of the hierarchy from all its lower parts and the criteria or items in each level [13]. Conventional AHP that requires the selection of arbitrary values in pair wise comparison may not be sufficient and uncertainty should be considered in some or all pair wise comparison values [14]. But this does not consider the inter-dependence of each KPI on other KPIs or objectives. So the drawbacks of AHP are: 1) it has only linear hierarchy structures that cannot calculate the inter-dependence weight between different levels; 2) it is static in decision evaluations and cannot measure inner and inter dependence weights for different objective; 3) it has no feedback mechanism which means that the evaluation from this approach is only at a single level of dependence. To overcome this, the Analysis Network Process (ANP) is utilized.

The Analytic Network Process (ANP) is the variant of the AHP that can be tailor-made for specific situations and can be used to overcome most the traditional problems of BSC implementation [15]. ANP itself enables the interrelationships among the decision levels and attributes to be taken into consideration in a more general form. In this case, ANP can be used as an effective tool in those particular cases where the interactions among the elements of a system form a network structure [16]. ANP models have two parts: the first is a control hierarchy or network of objectives and criteria that controls the interactions in the system under study; the second comprises the many sub-networks of influences among the elements and clusters of the problem, one for each control criterion [17]. ANP is capable of handling inter-relationships between the decision levels and attributes by obtaining the composite weights through the development of a "supermatrix" [18]. The supermatrix is actually a partitioned matrix, where each matrix segment represents a relationship between two components or

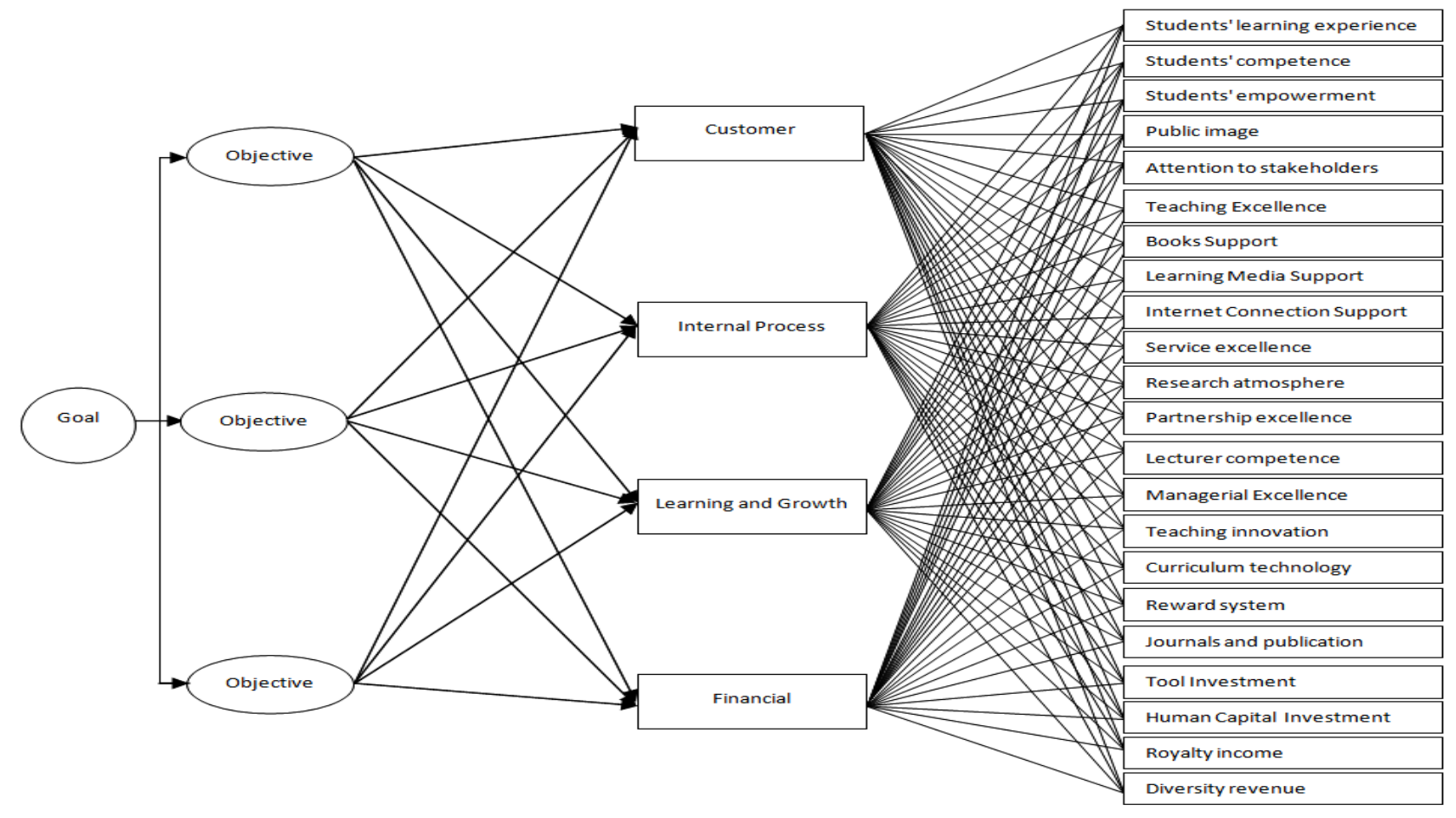

Figure 2. Balanced Scorecard Flowchart 
clusters in a system [16]. There are different variants of using ANP such as the conventional and fuzzy-based approach. In our approach, we will use the Fuzzy-ANP approach proposed by Chang [17] to determine the weights of each KPI by considering its interdependencies. This is because the fuzzy linguistic approach, by using the membership functions, can take into account approximate reasoning [20] and the intermediate or vagueness in the responses of the KPIs instead of the conventional numerical equivalence method [19]. So our approach of utilizing the Fuzzy ANP to determine the quality of education is as follows:

Step 1: Establish the general goal.

Step 2: Determine the objectives, which will lead to the goal.

Step 3: Determine the perspective under each objective, and key performance indicators.

Step 4: Develop an ANP structure for the oriented BSC (establishing connectivity and inter correlation among each KPI and objectives).

Step 5: Determine the local weights of objectives, perspectives, and KPIs using Chang's fuzzy AHP method.

Step 6: Define the local weights, global weight, relative weight, inner dependence weights, and interdependence for all KPIs and objectives captured from the previous step.

\section{Analytic Network Process to Determine the WEIGHT OF EACH KPI}

In this section, we will explain briefly the steps in determining the weight of each objective with respect to the goal to be achieved by considering the interdependencies between them. These steps are:

1. Calculate the pair wise comparison of each objective with respect to the goal.

2. Determine the weight for each objective.

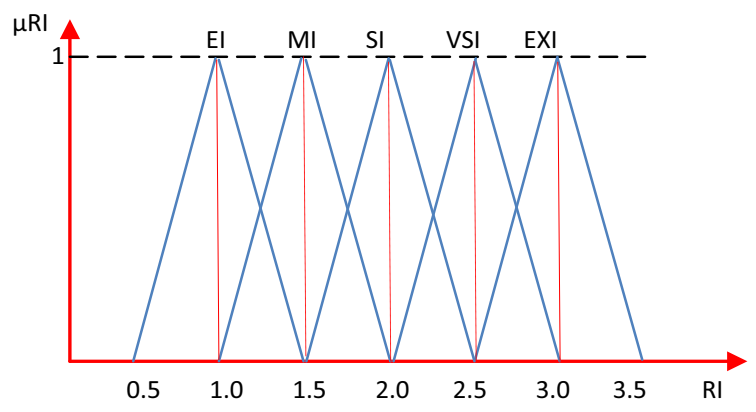

Figure 3. Linguistic Scale for Relative Importance

3. Determine the inner-dependency of each objective.

4. Determine the inter-dependency matrix and the weights between objectives.

5. Determine the global weight of the objectives by multiplying the analysis obtained in step 4 with that of step 2.

6. Use eigen values to estimate the relative weights of the objectives.

7. Check the consistency property of objectives to ensure that the judgments of decision makers are consistent.

Pair wise comparison between two objectives with respect to the goal is carried out on a 5 fuzzy set scale as shown in Table 2 and Figure 3.

Each fuzzy set represents a different level of importance and depending upon the level of importance of an objective to the goal, the corresponding level of fuzzy importance is assigned to it and the reciprocal value is assigned to the other objective.

This process is repeated for each objective and their weights are determined with respect to the goal as shown in Table 3.

The next step is to determine the level of inner

TABLE 2. LINGUISTIC SCALE FOR IMPORTANCE

\begin{tabular}{|c|l|l|l|l|}
\hline \hline $\begin{array}{c}\text { Level of } \\
\text { importance }\end{array}$ & \multicolumn{1}{|c|}{$\begin{array}{c}\text { Linguistic scale for } \\
\text { importance }\end{array}$} & $\begin{array}{c}\text { Triangular } \\
\text { fuzzy scale }\end{array}$ & $\begin{array}{l}\text { Triangular fuzzy } \\
\text { reciprocal scale }\end{array}$ & \multicolumn{1}{|c|}{ Explanation } \\
\hline \hline 1 & Just equal & $(1,1,1)$ & $(1,1,1)$ & $\begin{array}{l}\text { Two activities contribute equally the } \\
\text { same to objective }\end{array}$ \\
\hline 2 & $\begin{array}{l}\text { Equally Important } \\
\text { (EI) }\end{array}$ & $\begin{array}{l}\text { Two activities contribute equally to } \\
\text { objective }\end{array}$ \\
\hline 3 & $\begin{array}{l}\text { Moderately Important } \\
(\mathrm{MI})\end{array}$ & $(1 / 2,1,3 / 2)$ & $(2 / 3,1,2)$ & $\begin{array}{l}\text { Experience and judgment slightly favor } \\
\text { one over another }\end{array}$ \\
\hline 5 & $\begin{array}{l}\text { strongly important } \\
(\text { SI })\end{array}$ & $\begin{array}{l}\text { very strongly important } \\
\text { (VSI) }\end{array}$ & $(2,5 / 2,3)$ & $\begin{array}{l}\text { Experience and judgment strongly favor } \\
\text { one over another }\end{array}$ \\
\hline 6 & $\begin{array}{l}\text { extremely important } \\
\text { (EXI) }\end{array}$ & $(1 / 2,2 / 3,1)$ & $\begin{array}{l}\text { Activity is strongly favored and its } \\
\text { dominance is demonstrated in practice }\end{array}$ \\
\hline
\end{tabular}


Table 3. Local Weight Respect to Goal and Objective

\begin{tabular}{|c|c|c|c|c|}
\hline & $\mathrm{O}-1$ & $\mathrm{O}-2$ & $\mathrm{O}-3$ & Weight \\
\hline $\mathrm{O}-1$ & $(1,1,1)$ & $(1,3 / 2,2)$ & $(1 / 2,1,3 / 2)$ & 0.327 \\
\hline $\mathrm{O}-2$ & $(1 / 2,2 / 3,1)$ & $(1,1,1)$ & $(1 / 2,2 / 3,1)$ & 0.346 \\
\hline $\mathrm{O}-3$ & $(2 / 3,1,2)$ & $(1,3 / 2,2)$ & $(1,1,1)$ & 0.327 \\
\hline
\end{tabular}

\begin{tabular}{|c|c|c|c|}
\hline $\mathrm{O}-1$ & $\mathrm{O}-2$ & $\mathrm{O}-3$ & Weight \\
\hline "O-2 & $(1,1,1)$ & $(1 / 2,2 / 3,1)$ & 0.44 \\
\hline $\mathrm{O}-3$ & $(1,3 / 2,2)$ & $(1,1,1)$ & 0.56 \\
\hline c. & \multicolumn{3}{|c|}{ Inner dependency weight of the objective which respect to objective 2} \\
\hline $\mathrm{O}-2$ & $\mathrm{O}-1$ & $\mathrm{O}-3$ & Weight \\
\hline O-1 & (1,1,1) & $(1 / 2,1,3 / 3)$ & 0.5 \\
\hline $\mathrm{O}-3$ & $(2 / 3,1,4 / 2)$ & $(1,1,1)$ & 0.5 \\
\hline
\end{tabular}

\begin{tabular}{c|ccc}
\multicolumn{5}{l}{ d. } & \multicolumn{4}{l}{ Inner dependency weight of the objective which respect to objective 3 } \\
\hline $\mathrm{O}-3$ & $\mathrm{O}-1$ & $\mathrm{O}-2$ & Weight \\
\hline \hline $\mathrm{O}-1$ & $(1,1,1)$ & $(1,3 / 2,2)$ & 0.56 \\
$\mathrm{O}-2$ & $(1 / 2,2 / 3,1)$ & $(1,1,1)$ & 0.44 \\
\hline
\end{tabular}

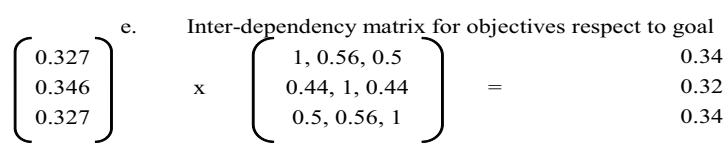

dependencies among the objectives. In our problem and according to the discussion with the experts, we determined that each objective is dependent on each other and hence the inner dependence matrix between the objectives is as shown in Figure 4.

To determine the effect of such inner dependencies between the objectives on the final weight which they will have on the goal, pair wise comparisons between each of them should be determined to ascertain their respective weights. Such analysis is represented in Tables 3(b-d). The final weights of each objective on the goal are determined by multiplying the inner dependence matrix with the respective weights is shown in Table 3(e). It can be seen that the weights determined for each objective with respect to the goal varies from the weight determined by considering the inner dependencies between them. This

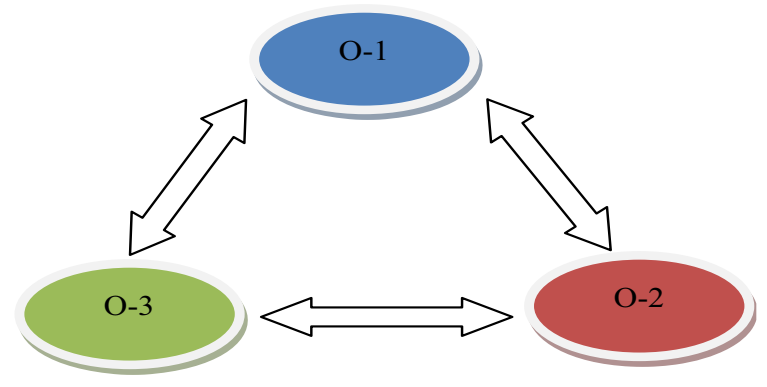

Figure 4. Relationship between Objectives

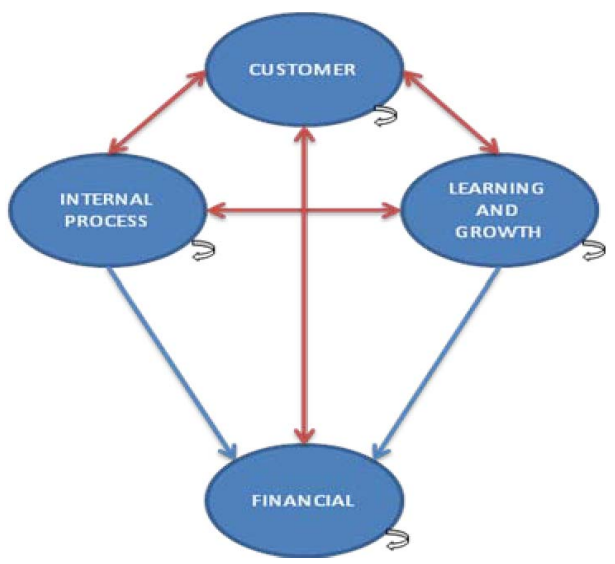

Figure 5. Relationship between Perspectives under Objective 1

process should be repeated for each perspective of the BSC and their relative weights should be determined. The next step is to determine the weight of each perspective with respect to the objectives and then consider the level of inner dependencies between them. In our approach we found the inner dependencies (represent by loop arrows) between the perspectives by interviewing the experts as shown in Figure 5.

Pairwise comparisons between these perspectives should be carried out as were done with the objectives and their global weights or importance to the objectives should be determined. Due to space limitations, in this paper we do not show the detailed process of determining the weights of the perspectives. Figure 6 represents the individual global weights of objectives in the BSC to determine the quality of education.

Once the weights for the different elements in the BSC have been determined, the next step is to determine the value of each KPI by using survey results and cumulate them to ascertain the quality of education. This will be discussed in the next section.

\section{ASCERTAINING THE QUALITY OF EDUCATION}

To determine the quality of education, we formulate a set of questionnaires which address all identified KPIs based on the higher education institution's long-term strategic planning. The objectives of this survey are not only to identify the most important to the least important of the KPIs based on the respondents' point of view, but also to define the relativity among different KPIs which will ascertain the quality of education. 




Figure 6. Key Performance Indicator's Weight

The survey is divided into 4 categories of respondents (student, education staff / lecturer, managerial staff / head of school and the local government). The surveys were conducted and collected from four different units, each of which had four classes. There are 50 students per class in each course. The survey data was collected from 20 lecturers, 5 local government representatives and 5 managerial staff. The questionnaire was divided into four sections addressing the perspectives in BSC, and each section had a different number of questions depending on the KPIs and performance indicators according to the identified KPIs. The survey had 130 questions. The course for which we conducted the survey had different units in it and we conducted the survey for each unit. The course was divided into four sections with 50 students in each section.

The survey was given to each of them and the respondents were asked to answer to each question in a range of $0-6$, with 0 representing the least satisfaction to the question and 6 representing the highest level of satisfaction. The value of each KPI was determined as the mean of the responses by the number of respondents and then multiplied with the respective global weight of the KPI as shown in Equation 1.

$\mathrm{vKPI}_{\mathrm{i}}=\mathrm{wKPI}_{\mathrm{i}} * \frac{\sum_{i=1}^{n} r K P I_{i}}{n}$

where: $w K \mathrm{KI}_{i}$ represents the global weight of $\mathrm{KPI}$, $\mathrm{rKPI}_{\mathrm{i}}$ represents the responses of $\mathrm{KPI} \mathrm{i}_{\mathrm{i}}$, $\mathrm{n}$ represents the number of respondents,

$\mathrm{vKPI}_{\mathrm{i}}$ represents the determined value of $K P I_{i}$

This process is repeated for each KPI according to the survey results and its value determined. The next step is to determine the value of each objective (level 2 of the BSC). This is determined by considering the level of interdependence of the BSC perspectives according to that objective (weights of each perspective according to that objective) and the value of the KPIs that come under each of them. This is determined by Equation 2 .

$\operatorname{vObj}_{\mathrm{i}}=\sum_{i=1}^{n} \operatorname{WPer}_{i} *\left(\sum_{j=1}^{m} v K P I_{j}\right)$

where: $\mathrm{VKPI}_{\mathrm{j}}$ represents the determined value of $\mathrm{KPI} \mathrm{j}_{\mathrm{j}}$ $m$ represents the number of KPI in perspective ${ }_{i}$, ${ }_{\text {wPer }}$ represents the weight of perspective $_{i}$, $n$ represents the number of perspectives,

$\mathrm{vObj}_{\mathrm{i}}$ represents the determined value of objective ${ }_{\mathrm{i}}$

Once the value of each objective has been determined, then the quality of education on the scale of $0-6$ can be determined by using equation 3

vGoal $=\sum_{k=1}^{o} W_{O b j k} * v O b j_{k}$

where $\mathrm{wObj}_{\mathrm{k}}$ represents the global weight of objective $\mathrm{k}_{\mathrm{k}}$, $\mathrm{vObj}_{\mathrm{k}}$ represents the value of objective $\mathrm{k}_{\mathrm{k}}$. 
By utilizing the proposed approach, the value of each KPI, perspective and objective can be determined based on the level of education that is being delivered. The poorer performing areas can be determined by the value of the determined KPIs, and the impact that they will have on achieving the overall goal can be ascertained. This will alert the decision maker to the need to take corrective actions against the non-performing KPIs that hinder the improvement of the quality of education to the desired level.

\section{CONCLUSION}

The BSC is a performance management system that enables an educational provider to translate its strategy and strategic planning into action. It considers not only the financial measures, but also other measures that must be considered by an organization whose aim is not just to make profit but also to provide a service to the community. In this paper, we proposed an approach that utilizes the Balanced Scorecard to ascertain the quality of education. By utilizing the proposed approach, the education provider can identify the different areas that are important to be considered and then determine its performance in each of them through a combination of quantitative and qualitative approach. The survey that was conducted has provided us with important information for carrying out the qualitative analysis to evaluate the recent changes and future considerations which may necessitate taking actions for the non-performing KPIs. The non-performing KPIs of an education provider can be identified and then strategies can be developed to improve its performance in them. In other words, this method facilitates the process of risk management that will lead to an improvement in the quality of education. But before carrying out the risk management, the level of severity according to which it should be carried out in each nonperforming KPI should be determined. For this task, the level of deviation of each KPI from its optimal point should be determined. Further after the analysis, policies have to be defined to address the non-perfoming KPIs. During this stage, as there may be more than one policy maker, having semantics associated with each KPI, perspective of BSC would be benefitial for decision makers when establishing policies to improve the quality of education itself under the particular condition. This is our future work.

\section{REFERENCES}

[1] K. Watkins. Human Development Report 2007/2008 [Online]. Available: http://hdr.undp.org/en/media/hdr 20072008 summary engli $\underline{\text { sh.pdf }}$

[2] A. M. Schneiderman, "Why Balanced Scorecards fail," Journal of Strategic Performance Measurement, vol. January, pp. 6-11, 1999.

[3] R. McAdam and E. O'Neill, "Taking a critical perspective to the European Business Excellence Model using the balanced scorecard approach: A case study in the service sector," Managing Service Quality, vol. 3, pp. 191-197., 1999.

[4] K. A. Hafner, "Partnership for performance: The balanced scorecard put to the test at the University of California," 1998.

[5] C. Papenhausen and W. Einstein, "Insights from the Balanced Scorecard: Implementing the Balanced Scorecard at a college of business," Measuring Business Excellence, vol. Vol. 10, pp. 15-22, 2006.

[6] R. S. Brown and P. Wohlstetter, "Developing a Performance Evaluation System for Charter Schools: The Balanced Scorecard Approach," Center on Educational Governance, Rossier School of Education, University of Southern California2003.

[7] R. S. Kaplan and D. P. Norton, The Strategy Focused Organization: Harvard Business School Press, 2001.

[8] P. R. Niven, Balance Scorecard Step-by-Step: John Wiley \& Sons, Inc, 2002.

[9] M. D. Nayeri, M.M. Mashadi and K. Mohajeri, "Universities Strategic Evaluation Using Balanced Scorecard," PWASET, vol. Vol. 27, pp. 332-337, 2008.

[10] T. M. Yek, Penney D and Seow A.C.H., "Using Balanced Scorecard (BSC) to Improve Quality and Performance of Vocational Education and Training (VET): A Case Study in Singapore," presented at the AARE Fremantle, Australia, 2007.

[11] T. H. Poister and G. D. Streib, "Strategic Management in the Public Sector: Concepts, Models, and Processes," Public Productivity \& Management Review, vol. Vol. 22, pp. 308325, 1999.

[12] M. Punniyamoorthy and R. Murali, "Balanced score for the balanced scorecard: a benchmarking tool," Benchmarking: An International Journal, vol. Vol. 15, pp. 420-443, 2008.

[13] L. M. Meade and J. Sarkis, "Analyzing organizational project alternatives for agile manufacturing processes: an analytical network approach," International Journal of Production Research, vol. 37, pp. 241-261, 1999.

[14] C.-S. Yu, "AGP-A HP method for solving group decisionmaking fuzzy AHP problems," Computers \& Operations Research, vol. 29, pp. 1969-2001, 2002.

[15] L. C. Leung, K.C. Lam and D. Cao, "Implementing the Balanced Scorecard Using the Analytic Hierarchy Process \& the Analytic Network Process," The Journal of the Operational Research Society, vol. 57, pp. 682-691, 2006.

[16] T. L. Saaty, "Time dependent decision-making; dynamic priorities in the AHP/ANP: Generalizing from points to functions and from real to complex variables," Mathematical and Computer Modelling, vol. 46, pp. 860-891, 2007.

[17] T. L. Saaty, "Multi-decisions decision-making: In addition to wheeling and dealing, our national political bodies need a formal approach for prioritization," Mathematical and Computer Modelling vol. 46, pp. 1001-1016, 2007.

[18] C. E. Bozdag, C. Kahraman and Da Ruan, "Fuzzy group decision making for selection among computer integrated manufacturing systems," Computers in Industry, vol. 51, pp. 13-29, 2003

[19] G.-S. Liang, "Personnel selection using fuzzy MCDM algorithm," European Journal of Operational Research, vol. 78, pp. 22-33, 1994. 